\title{
22. MAGNETIZATION AND PALEOMAGNETIC FIELD INTENSITY OF SELECTED SAMPLES FROM SITES 332, 334, and 335
}

\author{
C.M. Carmichael, Department of Geophysics, University of Western Ontario, London, Canada
}

\section{INTRODUCTION}

The project was designed to study the magnetization of samples at different depths for comparison with properties that had been inferred from studies of dredged specimens. It was intended to test measures of paleomagnetic field intensity as an additional means of correlating and distinguishing flow and intrusive units.

The samples consisted of 31 slices, 1 to $2 \mathrm{~cm}$ in thickness, cut from 2.5 -cm-diameter cylinders drilled transverse to the large core. Of these, 12 were from Cores 36 and 37 of Hole 332B, 16 were from Cores 6, 10 , and 13 of Site 335 , and 3 were from Site 334 with one each from Cores 20,22, and 24. The deepest samples were from Hole 332B at about 600 meters and the shallowest were the Site 334 samples starting at about 300 meters. Most of the samples are typical submarine basalts having abundant small magnetite grains usually with a skeletal mode of growth (Plate 1) similar to those dredged near the Mid-Atlantic Ridge at $45^{\circ} \mathrm{N}$ (Carmichael, 1970). The samples show varying amounts of alteration with the most severe occurring near veins. The alteration ranges from minor small patches of reddened silicate and some maghemite around the edges of the magnetite to almost complete reddening with the formation of iddingsite and conversion of the magnetites to hematite. The intensity of magnetization is strong, similar to that of dredged samples, with most being in the range of 3 to $5 \times 10^{-3} \mathrm{emu} / \mathrm{cm}^{3}$. The magnetization is also relatively hard so that the direction of magnetization of most samples changed by no more than $10^{\circ}$ to $15^{\circ}$ on alternating field or thermal demagnetization.

\section{HOLE 332B}

The samples from Hole 332B span a change in polarity from normal to reversed over a distance of about 15 meters. The six upper samples from Sections 1, 2, and 3 of Core 36 are spaced from a half a meter to a meter apart and have shallow positive inclinations. The lower six from Sections 5 and 6 of Core 36 and Sections 1 and 2 of Core 37 are similarly spaced and have negative inclinations. Foraminifera-bearing sediments separate the normal and reversed samples, suggesting a time interval. Alteration is variable, but quite marked around numerous carbonate and chlorite veins that are present in both cores.

There is evidence both for and against the recording of the field as it reversed. In favor is the steady shallowing of the negative inclinations toward the transition and a less marked increase in the positive inclinations above it. The lower samples have $50^{\circ}$ to $60^{\circ}$ cleaned inclinations similar to the present field at the site, but the upper ones are shallow, reaching no more than $25^{\circ}$. Evidence against the recording of a reversal in progress is the uniformly strong intensity of magnetization for all the samples with no indication of those at the transition being magnetized in a weaker field. Attempts at measuring the intensity of the field across the transition were not successful as discussed below.

Sample $37-2,102-105 \mathrm{~cm}$ is part of a chloritecontaining glassy layer that forms the base of the igneous unit. It has as its magnetic constituent abundant fine grains of magnetite that have separated out of the glass (Plate 1). The grains lie in roughly parallel swaths following the boundaries of the glassy regions and are so numerous as to render the glass almost opaque. This sample is the strongest magnetically of the set, having a magnetization of $20 \times 10^{-3} \mathrm{emu} / \mathrm{cm}^{3}$.

\section{SITE 334}

Of the three samples from Site 334 the one from Core 20 has a positive inclination whereas those from Cores 22 and 24 have negative inclinations. Sample 22-2, 52$55 \mathrm{~cm}$ is serpentinized peridotite that contains considerable fine-grained magnetite similar to 332B-37-2, $102-105 \mathrm{~cm}$. Sample $24-3,55-58 \mathrm{~cm}$ is a coarse-grained serpentinized olivine gabbro in which the magnetic constituent is some pyrrhotite among abundant grains of pyrite. It is the weakest sample of the set having a magnetization of $0.04 \times 10^{-3} \mathrm{emu} / \mathrm{cm}^{3}$.

\section{SITE 335}

The 16 samples from Site 335 contain 9 that are closely spaced across a single 60 -cm-thick pillow. The top and bottom samples of the set 6-1, 53-55 cm through 6$1,129-131 \mathrm{~cm}$ are very fine grained and must be very close to the chilled margins. The uniform declination of the 9 samples confirms the way in which the various pieces were fitted together. In addition, there are two samples from a unit just above this one and another from just below it. All of the samples from Core 6 and also those from the deeper Cores 10 and 13 have negative inclinations in the $50^{\circ}$ to $70^{\circ}$ range similar to, though a bit steeper, than the present field at the site. If the majority of the core from the rest of Site 335 has similar magnetization to that from Cores 6,10 , and 13 , then the negative magnetic anomaly measured over the site can easily be accounted for by the remanent magnetization of the basalt recovered. This is compatible with the prediction made by Carmichael (1970) that the upper few hundred meters of lavas would account for the magnetic anomalies. The prediction is not supported by data from Hole 332B, however, where the unusually large percentage of shallow inclinations requires a thickness exceeding the 600 meters drilled. 


\section{PALEOMAGNETIC FIELD INTENSITY}

Attempts to measure the intensity of the field in which the samples formed were not successful with the possible exception of two samples. The known presence of some maghemite in the magnetites mades intensity measures involving heating rather uncertain as the maghemite breaks down to hematite in an irreversible reaction. An even greater problem is the tendency of the amount of magnetic material, as indicated by the saturation remanence, to increase markedly on heating. With few exceptions the saturation remanent magnetization after heating, SRM(h), was 2 to 5 times as large as the saturation remanent magnetization of the natural sample, SRM, particularly in the low to intermediate coercive force ranges. Most of the heating to produce a thermoremanence was carried out in vacuum which prevented reddening of the silicates and protected the magnetites from oxidizing to hematite. Repeated heating in air caused the silicates to become reddened and most of the skeletal magnetite to change to hematite, but even in this condition the SRM(h) was greater than the SRM. There is no obvious source of this increased magnetization in polished sections though it may be due to new oxide being precipitated out of glass on a fine scale.

The large increase in the amount of magnetic material on heating precludes the use of these samples for paleointensity measurement. There are only two samples which had small changes in saturation remanence on heating and which also contain little maghemite as indicated by the reproducibility of the shape of the zero field thermal demagnetization curves before and after heating. These are the magnetite in glass Sample 332B-37-2, 102-105 cm and a fine-grained chilled margin basalt Sample 335-6-1, 53-55 cm. The magnetic characteristics of these samples are shown in Figure 1 and Table 1.
The paleomagnetic field intensity is calculated by comparing the NRM to the TRM, produced in $0.5 \mathrm{oe}$, relative to the saturation remanence before and after heating, with all remanences measured after successive stages of AF demagnetization. The paleointensity is given by

$$
\frac{\mathrm{NRM}}{\operatorname{SRM}} / \frac{\operatorname{TRM}(0.5)}{\operatorname{SRM}(\mathrm{h})} \times \text { latitude factor }
$$

A latitude factor corrects for the change of intensity with latitude using the latitude variation of the present field. In this case the factor is 1.1 because the field at the site is a little greater than 0.45 oe. This method gave reasonable values of intensity for some of the recent lavas from Surtsey (Carmichael, 1974) where there was a small increase in saturation remanence on heating, but in the case of the present samples the increase is too large.

It is my conclusion that measures of paleomagnetic field intensity cannot be used to correlate or distinguish flow units in these submarine basalts. The data upon which these conclusions are based are contained in Chapters 2, 4, and 5, this volume.

\section{ACKNOWLEDGMENTS}

I wish to thank F. Aumento who carefully selected these samples and to acknowledge the assistance of the National Research Council of Canada (Research Grant A1776).

\section{REFERENCES}

Carmichael, C.M., 1970. The mid-Atlantic ridge near $45^{\circ} \mathrm{N}$. VII: Magnetic properties and opaque mineralogy of dredged samples: Canadian J. Earth Sci., v. 7, p. 239-256. , 1974. A test of paleomagnetic intensity methods using recent lavas, and implications for anomaly interpretation: J. Geophys., v. 40, p. 489-500. 

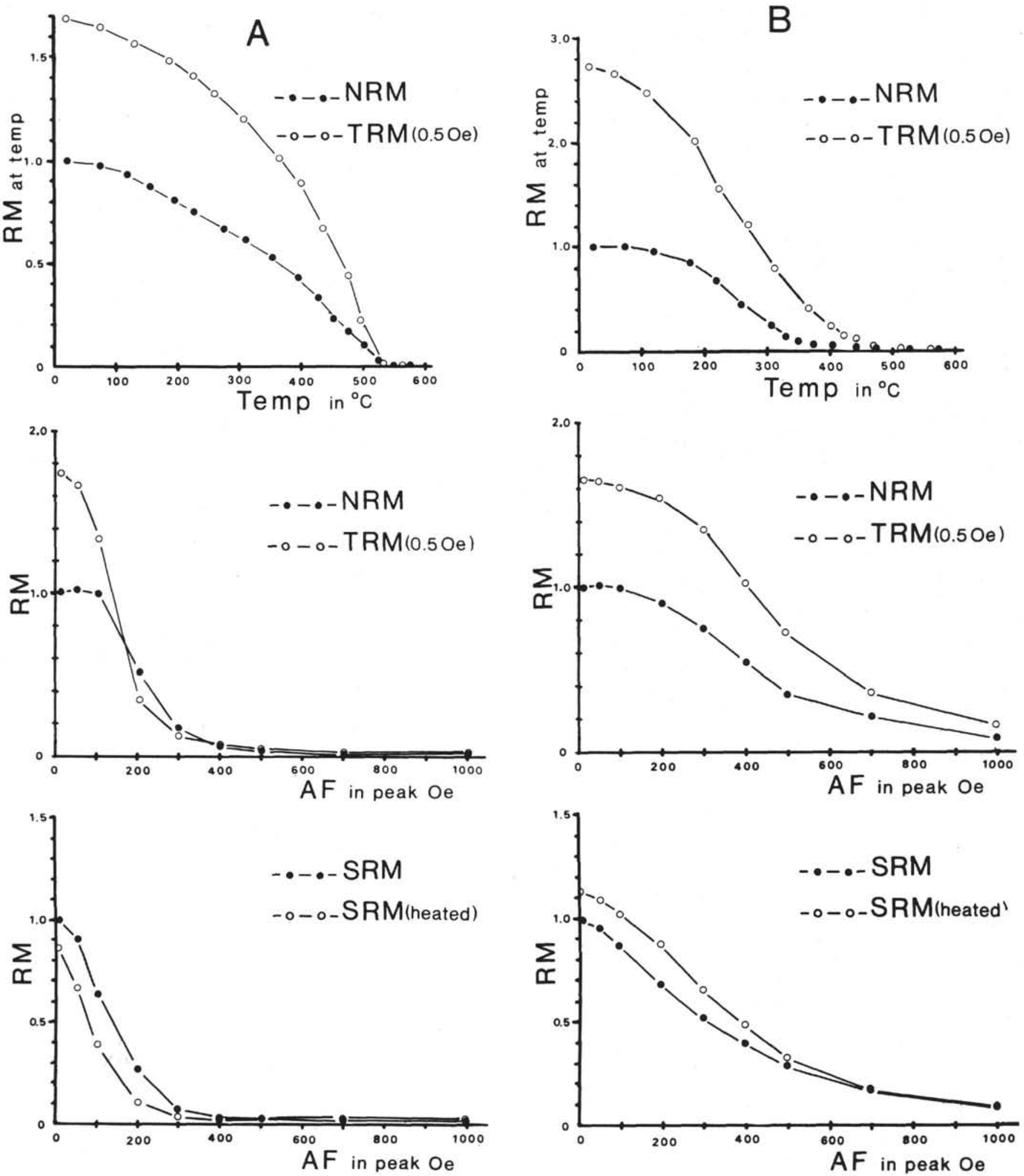

Figure 1. Magnetic data for Sample 332B-37-2, 102-105 cm are shown in (A) and for Sample 335-6-1, 53-55 cm (2B) in (B). The top curves show the NRM and the TRM produced in 0.5 oe measured in zero field at the temperature indicated. The middle and bottom curves show the alternating field demagnetization of the NRM, TRM (0.5), and the saturation remanences before and after heating - SRM and SRM( $h)$. 
TABLE 1

Paleomagnetic Field Intensity Calculations for Three Samples of Submarine Basalt ${ }^{\text {a }}$

\begin{tabular}{|c|c|c|c|c|c|}
\hline $\begin{array}{c}\mathrm{AF} \\
\text { (oe peak) }\end{array}$ & $\begin{array}{c}\text { NRM } \\
\left(10^{-3} \mathrm{emu} / \mathrm{cm}^{3}\right)\end{array}$ & $\begin{array}{c}\text { SRM } \\
\left(10^{-3} \mathrm{emu} / \mathrm{cm}^{3}\right)\end{array}$ & $\begin{array}{c}\operatorname{TRM}(0.5) \\
\left(10^{-3} \mathrm{emu} / \mathrm{cm}^{3}\right)\end{array}$ & $\begin{array}{c}\operatorname{SRM}(\mathrm{h}) \\
\left(10^{-3} \mathrm{emu} / \mathrm{cm}^{3}\right)\end{array}$ & $\begin{array}{c}\text { PI } \\
\text { (present } \\
\text { field is } \\
1.0 \text { ) } \\
\end{array}$ \\
\hline \multicolumn{6}{|c|}{$332 \mathrm{~B}-37-2,102-105 \mathrm{~cm} \mathrm{CA} \mathrm{CA}$} \\
\hline 0 & 24.6 & 1316 & 43.5 & 1107 & 0.52 \\
\hline 50 & 24.9 & 1179 & 41.0 & 859 & 0.49 \\
\hline 100 & 24.0 & 830 & 33.2 & 505 & 0.48 \\
\hline 200 & 12.3 & 357 & 8.31 & 132 & 0.60 \\
\hline 300 & 3.85 & 98.7 & 3.27 & 42.7 & 0.56 \\
\hline 400 & 0.896 & 28.3 & 1.46 & 22.1 & 0.53 \\
\hline 500 & 0.496 & 13.2 & 1.11 & 13.2 & 0.49 \\
\hline \multicolumn{6}{|c|}{$335-6-1,53-55 \mathrm{~cm}(2 \mathrm{~B}) \mathrm{CA} \mathrm{CA}$} \\
\hline 0 & 4.99 & 213 & 8.30 & 241 & 0.75 \\
\hline 50 & 5.07 & 205 & 8.14 & 233 & 0.78 \\
\hline 100 & 5.00 & 179 & 8.01 & 220 & 0.84 \\
\hline 200 & 4.43 & 144 & 7.72 & 185 & 0.81 \\
\hline 300 & 3.71 & 111 & 6.79 & 141 & 0.76 \\
\hline 400 & 2.58 & 84.9 & 5.10 & 103 & 0.68 \\
\hline 500 & 1.82 & 61.8 & 3.55 & 71.2 & 0.65 \\
\hline 700 & 1.05 & 36.9 & 1.72 & 36.5 & 0.66 \\
\hline 1000 & 0.395 & 16.4 & 0.637 & 16.2 & 0.67 \\
\hline \multicolumn{6}{|c|}{$332 \mathrm{~B}-36-6,66-67 \mathrm{~cm} \mathrm{CA} \mathrm{CA}$} \\
\hline 0 & 3.05 & 176 & 8.12 & 472 & 1.11 \\
\hline 50 & 3.10 & 140 & 7.81 & 424 & 1.32 \\
\hline 100 & 2.69 & 78.5 & 7.45 & 336 & 1.70 \\
\hline 200 & 1.48 & 33.9 & 5.84 & 177 & 1.46 \\
\hline 300 & 0.742 & 14.4 & 4.17 & 102 & 1.39 \\
\hline 400 & 0.374 & 9.16 & 2.32 & 50.5 & 0.98 \\
\hline 500 & 0.244 & 5.98 & 1.30 & 25.7 & 0.89 \\
\hline 700 & 0.0956 & 3.12 & 0.516 & 8.99 & 0.59 \\
\hline
\end{tabular}

Note: Samples 332B-37-2, 102-105 cm and 335-6-1, 53-55 cm (2B) y ield paleointensity values of about 0.5 and 0.7 times the present field, respectively. Sample $332 \mathrm{~B}-36-6,66-67 \mathrm{~cm}$ is typical of the remaining samples for which reliable paleointensities cannot be obtained due to more severe alteration on heating.

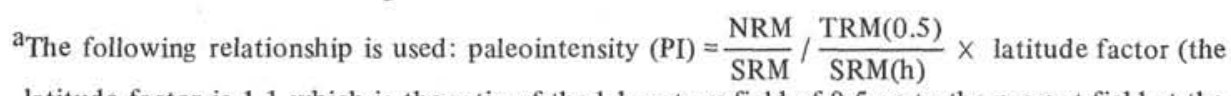
latitude factor is 1.1 which is the ratio of the laboratory field of 0.5 oe to the present field at the site). 



\section{PLATE 1}

Photomicrographs of polished sections.

Figures 1,2 Swaths of light gray magnetite grains separated out of glass in Sample 332B-37-2, 102-105 cm where 2 is the area outlined in white in 1.

Figures 3, 4 Same area of Sample 335-6-1, 53-55 cm (2B) in which small magnetite grains show light gray in 1 under reflected light and black in 2 under transmitted light.

Figures 5,6 Larger than usual skeletal magnetite grain in Sample 332B-36-6, 66-67 cm which is similar to most of the samples. White edges on the large magnetite grain consist of maghemite (Mh). Magnetic data for these samples are given in Table 1 and Figure 1. 


\section{PLATE 1}
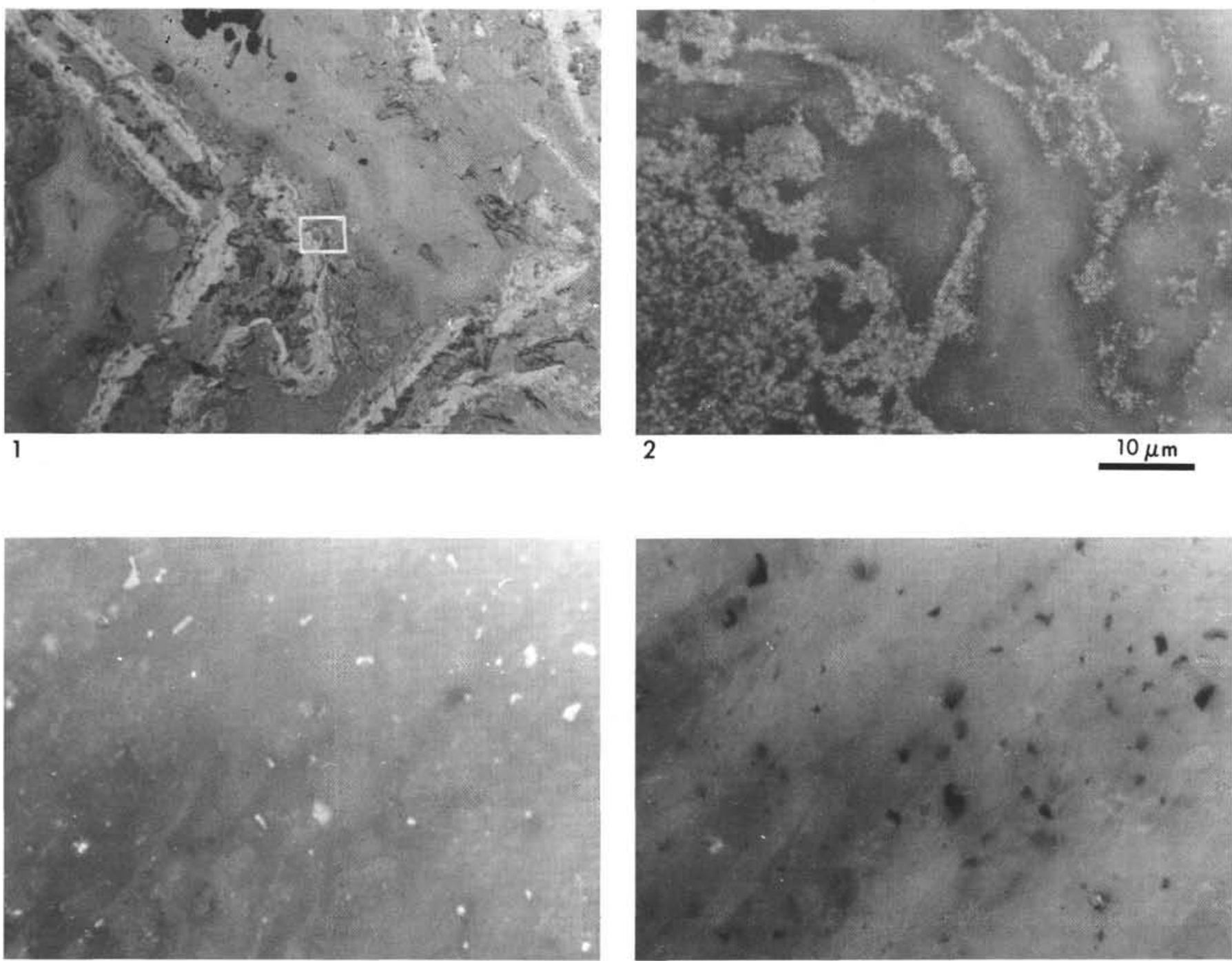

$310 \mu \mathrm{m}$

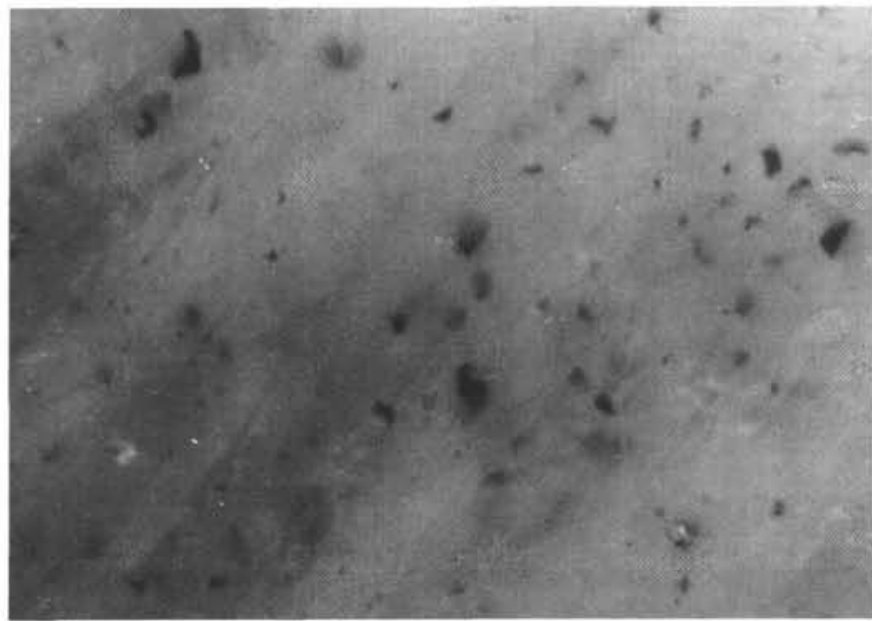

\section{$10 \mu \mathrm{m}$}

\section{4}
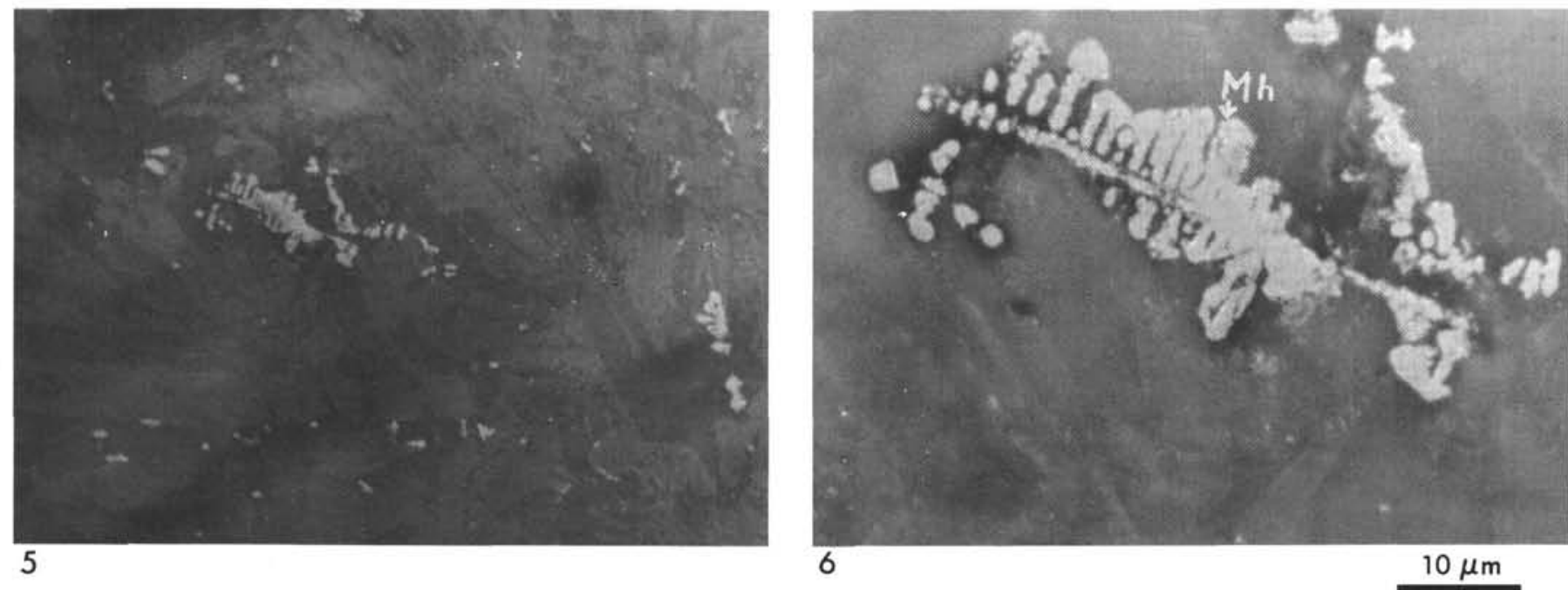